\title{
Socialismo ou cidadania planetária? Os paradigmas educacionais dominantes e a crítica marxista
}

Susana Vasconcelos Jimenez ${ }^{1}$

Essa comunicação refere-se a uma pesquisa voltada para o exame das principais teorizações que têm dominado o cenário pedagógico, sob o crivo da propalada crise dos paradigmas das ciências sociais.

Parte-se do pressuposto de que o processo de construção de um conhecimento efetivamente crítico e conseqüente exige a recusa de qualquer postura metodológica que, pautando-se por critérios de validade da esfera do pragmatismo ou de qualquer forma de irracionalismo subjetivista, possa confinar o real à esfera fenomênica, interceptando, assim, por princípio, a relação entre conhecimento e transformação radical da realidade.

Esta consideração torna-se particularmente necessária, num momento em que o capitalismo, vem impondo um magnânimo processo de reestruturação, acompanhado de um discurso que delineia a relação trabalho-educação a partir de novos conceitos e categorias não-classistas, ou seja, que representam a renúncia às idéias de trabalho e práxis social e abdicam da formação de uma consciência crítica que aponte para a superação do capital, com sérios efeitos sobre os programas de formação do educador.

Se a perspectiva marxista, como sabemos, radica-se na centralidade do trabalho e do movimento das classes sociais no entendimento da sociabilidade, já na vertente dominante, de cunho liberal, dois elementos, intimamente relacionados, ocupam destaque: a desqualificação da crítica radical ao capitalismo e a aposta na gestão competente do capital.

- - - - - -

1 Professora da Universidade Estadual do Ceará

cadernos cemarx, $n^{0} 2-2005 \mid 101$ 
Tal orientação vem sendo reforçada, contemporaneamente, por uma gama de visões pós-marxistas, que, não obstante insurjam-se, em alguma medida, contra os conteúdos e estratégias capitalistas, reforçam a ofensiva antimarxista, que, no mundo acadêmico vem sistematizando-se como epistemologias de um liberalismo recapitulado, que alinham, sob o estatuto da modernidade, quaisquer suposições que recusem a matéria, em sua contraditoriedade dialética, como realidade fundante da história.

Movidos, fundamentalmente, pela legítima aversão às inúmeras distorções de cunho economicista e determinista imputadas historicamente à herança marxiana, críticos de todos os matizes vêm propondo uma gama de paradigmas alternativos para a ortodoxia marxiana. uma gama de paradigmas alternativos. Estes, não obstante variações de expressão, complexidade e alcance, têm em comum o clamor pela reinstauração do primado da individualidade/ subjetividade, supostamente sufocada nos ditames dessa mesma ortodoxia.

Nesse quadro sombrio, o marxismo vê-se constrangido a professar um mea culpa contrito, impondo-se o recolhimento nas sombras do tempo pretérito, ou, na melhor das hipóteses, a abertura ao diálogo com os chamados novos paradigmas - erigidos, diga-se de passagem, em nome da mais recente tentativa de sepultamento do velho Marx - para, com esses, compor a pluralidade de olhares sociológicos exigida pela recém-alcançada complexidade das relações sociais da era tecnológica.

Tal fenômeno insere-se num contexto marcado pelo que Mészáros² define como uma crise estrutural do capital, distinta das crises cíclicas que marcaram sua trajetória, a qual, tomando proporções e intensidade inéditas na história moderna, aguça de modo particularmente feroz, o caráter de destrutividade desse sistema.

Segundo esclarece Antunes, como resposta à crise, “...empreendeu-se um processo de reorganização do capital e de seu sistema ideológico e político de dominação"3 "...passando-se a praticar uma forma de envolvimento manipulatório levado ao limite"4.

A educação é, então, solicitada, com particular premência, a criar as disposições ideológicas, nos termos de Leher em Da Ideologia do Desenvolvimento à Ideologia da

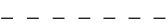

2 István Mészáros, "O Marxismo Hoje" (Entrevista). In: Crítica Marxista, n.2, São Paulo, Editora Brasiliense, 1995, pp.129-137 e do mesmo autor: Beyond Capital. London, Merlin Press, 1995a.

3 Ricardo Antunues, Os Sentidos do Trabalho: Ensaio sobre a afirmação e a negação do trabalho. São Paulo, Editora Boitempo, 1999, p.31.

4 Idem, p.190

102 Socialismo ou cidadania planetária? Os paradigmas educacionais dominantes e a crítica marxista 
Globalização, necessárias à adesão dos trabalhadores ao projeto do capital.

Mais ainda, o ideário da qualidade total invadiu os meios educacionais, acoplando-se ao modelo de competências, responsável pela formação do novo trabalhador, que deve, principalmente, saber-ser: polivalente no trato dos novos instrumentos de trabalho, ágil e flexível no raciocínio e na tomada de decisões, além de cooperativo e detentor da sempre louvada inteligência emocional, atributos capazes de garantir-lhe a sobrevivência num mundo (e num mercado) em constante mutação.

A noção de classe trabalhadora dissolve-se, aqui, no individualismo exacerbado, na busca frenética, cotidianamente incentivada, pela aquisição do conjunto de competências (do qual não está ausente a própria agressividade competitiva, a disponibilidade absoluta de aceitar passivamente as regras do jogo empresarial e a crença mística no poder do pensamento positivo...), condição para o milagre do indivíduo abençoado, e isolado, que encontra o seu lugar ao sol no mercado de trabalho.

Sob o poder metabólico do capital (para fazer uso da precisa formulação de Mészáros), a educação é, por conseguinte, premida a subordinar-se aos interesses do capital em crise, aprofundando a privatização, o aligeiramento e a fragmentação da atividade educativa e, ao mesmo tempo, chamando para o campo do idealismo mais tacanho, a direção teórico-prática da formação do educador.

Receituários da esfera do tecnicismo como do humanismo - a rigor e historicamente contrapostos - conjugam-se para expurgar da formação do educador, quaisquer resquícios de uma reflexão radicalmente crítica e contextualizada do fenômeno educativo. As múltiplas teorizações representam, então, a renúncia a uma perspectiva educacional fundada nas idéias de trabalho e práxis social, abdicando da formação de uma consciência crítica que aponte para a superação do capital, isso feito pela introdução ou (principalmente) reedição de categorias não classistas que atendem pelas denominações de globalização, holismo, cidadania, planetariedade, sustentabilidade, dialogicidade, transdisciplinaridade..., como as empregada por Gadotti e seus colaboradores no livro Perspectivas atuais da educação.

Outro exemplo: na edição de agosto de 2002, a Revista Nova Escola louva, em sua reportagem de capa, um elenco de pensadores que configurariam a vanguarda da educação. Referência obrigatória da formação do educador, os franceses Perrenoud e Morin; os espanhóis Coll e Hernández; o português Nóvoa; e o colombiano Toro anunciam a nova educação, a educação dos novos tempos, obtendo, no processo, memoráveis picos editoriais. Esse fato é digno de nota em um país que produziu um Paulo Freire, um Florestan Fernandes, ou um Dermeval Saviani, e onde outros pes-

cadernos cemarx, $\Pi^{0}-2-2005 \quad \mathbf{1 0 3}$ 
quisadores se dedicaram ao trabalho de decifrar o pensamento educacional de Antonio Gramsci no torvelinho de seus escritos do cárcere.

Arautos da modernidade, os novos pensadores "ressignificam" a educação, com vistas à inserção do aluno, da escola e do próprio país no mundo globalizado, no qual todos aprenderão a conviver, através de um processo educacional comprometido com a cultura da paz e a consciência planetária. Bebendo em fontes diversas, que parecem adaptar ideologicamente Dewey, Piaget, ou Freire; inspirando-se, ainda mais, em Maturana e Boff, compõem um mosaico eclético de suas lições para a educação e para a vida no século $\mathrm{XXI}^{5}$, atestando, que, também no plano teórico, tudo há que ser resolvido pela via do acordo, do somatório consensual de idéias, desde que legitimem o projeto de preservação da sociedade do capital.

Os discursos que proferem os diferentes paradigmas indicam que, não obstante a pretensão, em alguns casos, de firmar-se como contraposições ${ }^{6}$, esses, longe de se contrariarem, se harmonizam, uma vez que todos, invariavelmente, parecem adotar, cada um a seu modo, como base de sua raison d'être, o mesmo ponto de partida - o advento da assim chamada sociedade da informação; e o mesmo ponto de chegada a educação para a conquista da cidadania.

O ajustamento à presente ordem é, igualmente, o limite da crítica: reflexões críticas pontuais são, sim, recomendadas, conquanto não transcendam a esfera cotidiana, não se ocupem do desvelamento dos determinantes do real, pois, à realidade cumpre adaptarmo-nos, tout court, abrigando-nos de seus males e beneficiando-nos de seus tesouros. Essa façanha estará a cargo de professores, como quer Perrenoud, que ar-

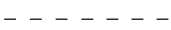

5 Segundo a matéria em foco, a fórmula do sucesso dos chamados novos pensadores da educação residiria no fato de que: “0 'negócio' deles é reprocessar idéias já largamente difundidas (e aceitas) e apresentá-las numa linguagem fácil, objetiva e coerente com as necessidades atuais" (Marangon, Cristiane e Lima, Eduardo - "A vanguarda da Educação". Revista Veja, Edição 154. Editora Abril, Agosto, 2002:4).

6Este parece ser o caso de dois paradigmas centrais da formação do educador, representados pela pedagogia das competências, por um lado; e pela proposta de formação do professor crítico-reflexivo, por outro. Expurgado pela crítica, empreendida nacional e internacionalmente, de seu caráter essencialmente praticista e individualista e pretendendo-se aberto à consideração das implicações políticas e sociais do ato de ensinar, o conceito de professor reflexivo, advindo de uma apropriação das idéias de Schön, do Massachussets Institute of Technology, e rebatizado como professor (ou intelectual) crítico-reflexivo, impôs-se como referência, em contraposição à pedagogia das competências. Em relação à questão, julgamos por bem não dar o debate por encerrado, tentando, no seio da pesquisa, qualificar o conteúdo e o alcance da crítica pretendida pelos adeptos da proposta voltada para a formação do professor crítico-reflexivo, do ponto de vista de sua abrangência, consistência e radicalidade.

104 Socialismo ou cidadania planetária? Os paradigmas educacionais dominantes e a crítica marxista 
mem (sic!) as crianças e os adolescentes para resistir às manipulações, receber criticamente as novas tecnologias da informação, aproveitando-se de seus recursos genuinamente educativos, e desviando-se, por exemplo, do mundo da pedofilia, ou da propaganda neonazista naqueles, igualmente, embutidas...

De todo modo, desenvolvendo as afamadas dez competências, propostas por Perrenoud e praticando o currículo por projetos (Hernández), por exemplo, o professor estará apto a desenvolver em seu aluno, os códigos da modernidade formulados por Toro, possibilitando que o mesmo se desenvolva como ser integral - razão, emoção, intuição, corporeidade - capaz de articular sua condição de indivíduo autônomo e dialógico, àquela de cidadão do mundo, ecologicamente responsável, fagulha interativa da energia cósmica universal.

Individualidade e totalidade reeditam-se de forma rigorosamente divorciada da necessária radicalidade ontológica, saltando por cima das mediações concretas atadas ao complexo de determinações econômico-políticas postas pelas relações socais, valendo observar, com Oldrini ${ }^{7}$, que o pressuposto de uma universalidade abstrata pertence à bagagem de mistificações ideológicas típicas da metafísica burguesa.

Além disso, pela voz dos novos pensadores, tudo - do desemprego à destruição ecológica do planeta - se resolverá na e pela educação, o que, aliás, traduz a antiqüíssima e mistificadora crença na educação como panacéia de todos os males sociais, invariavelmente trazida à tona, quando as forças sociais em ebulição tentam colocar em cheque o projeto do capital.

Com efeito, além de velhas verdades parciais, deslocadas dos projetos históricos em que se gestaram, o que se reedita, uma vez mais, na história das idéias pedagógicas, através da insurgência dos ditos novos paradigmas, é, essencialmente, o movimento de interdição, no seio da academia, do pensamento radicalmente crítico e revolucionário, a partir do qual, o campo educativo, via de regra aprisionado à esfera didática e psico-pedagógica, alarga seus horizontes em busca do entendimento do fenômeno educativo referido à centralidade do trabalho, articulando, ainda mais, o movimento teórico-prático de busca de soluções no plano pedagógico à luta pela superação do capital.

As teorizações vigentes no campo da formação docente embargam uma leitura

$-\cdots+-\cdots$

7 Guido Oldrini, "Lukács e o caminho marxista ao conceito de pessoa". In: Revista Práxis, n.3, Belo Horizonte, 1995.

cadernos cemarx, $n^{0}-2-2005 \mid \mathbf{1 0}$ 
contextualizada e crítica da realidade sócio-educacional à luz das complexas determinações em que esta se insere, ao mesmo tempo em que desqualificam a formulação de perspectivas superadoras do caldo eclético de paradigmas, os quais, vale enfatizar, permitem casar a racionalidade competitiva a um ideário espiritualista, coroado, com a apologética da cidadania ${ }^{8}$.

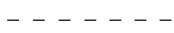

8 A noção de cidadania, ocultando, precisamente, o caráter de classe da sociedade, é confortavelmente adotada como o princípio norteador da prática educativa, passando a constituir-se o denominador comum, no qual se encontram e se identificam interesses, até há algum tempo, tidos como antagônicos. Para uma discussão aprofundada sobre a questão, cf. I. Tonet, Educação, Cidadania e Emancipação. Tese de Doutorado. São PauIo, UFScar, 2001.

106 Socialismo ou cidadania planetária? Os paradigmas educacionais dominantes e a crítica marxista 